\title{
Interactive comment on "Rapid increase in summer surface ozone over the North China Plain during 2013-2019: a side effect of particulate matters reduction control?" by Xiaodan Ma et al.
}

Xiaodan Ma et al.

2862185955@qq.com

Received and published: 28 September 2020

The comment was uploaded in the form of a supplement:

https://acp.copernicus.org/preprints/acp-2020-385/acp-2020-385-AC2-supplement.pdf

Interactive comment on Atmos. Chem. Phys. Discuss., https://doi.org/10.5194/acp-2020-385, 2020. 